${ }^{16}$ Harrington JM, Shannon HS. Survey of health care in British medical laboratory workers. $\mathrm{Br} \mathrm{Med} \mathcal{F} 1977 ; \mathrm{i}: 626-8$.

17 Department of Health and Social Security. Health Circular HC(79)3. London: DHSS, 1979.

18 Department of Health and Social Security. Control of laboratory use of pathogens very dangerous to humans. London: DHSS, 1976.

19 Department of Health and Social Security. Interim Advisory Committee on Safety in Clinical Laboratories. Bulletin No 1, January 1980 (G/H118) 165).

${ }^{20}$ Rankine AD. Laboratory safety. Lancet 1979,ii:1244.

21 Howie Sir James. Reducing infection risks in clinical laboratories. Med Tech Sci 1979;12:23-5.

${ }^{22}$ Royal Institute of Chemistry. Code of practice for chemical laboratories. London: RIC, 1976.

${ }^{23}$ University of Manchester Institute of Science \& Technology. Safety Manual. Manchester: UMIST, 1973.

${ }^{24}$ Collins CH. Safety in pathology laboratories: bibliographies. London: Institute of Medical Laboratory Sciences, 1976 and 1978.
25 Department of Health and Social Security. Hospital building note. No 15: Pathology laboratories. London: DHSS, 1973 (new edition in preparation).

${ }^{26}$ Grist NR. Hepatitis in clinical laboratories 1975-6. $\mathcal{F}$ Clin Pathol 1978;31: 415-7.

27 Public Health Laboratory Service, unpublished. Comm Dis Rep 79/48; 1979.

${ }^{28}$ Collins CH. Safety on the cheap. Med Lab World 1979 ;3:14-9.

29 United States Department of Health Education and Welfare. Classification of etiologic agents on the basis of hazard. Atlanta: Centre for Disease Control, 1974

${ }^{30}$ Center for Disease Control. Laboratory-associated typhoid fever. Morb Mort Wkly Rep 28/44; Nov, 1979.

s1 Pike RM. Laboratory associated infections: summary and analysis of 3921 cases. Health Lab Sci 1976;13:105-14.

(Accepted 19 February 1980)
Our patient, a 46-year-old radio technician, became critically ill on 2 January 1979 and started a $25000 \mathrm{~km}$ journey by air under special care. An Ilyushin-14 had crashed on take-off at the Soviet Antarctica base at Molodezhnaya (67.45 S, 46.00 E) on the Prince Olaf Coast of Enderby Land. Three crew members were killed, four had fractured legs and one a severe head injury, and 11 escaped unharmed. In Antarctica the various scientific stations have doctors and medical equipment, but there are limits to what can be managed on that harsh continent. The sole air base for external communications is at McMurdo (77.51 S, 166.37 E) with an ice runway that functions only in the southern summer. The US Antarctic Program with Operation Deep Freeze has servicing flights with military aircraft, jet Starlifter, and turboprop Hercules with skis between there and Christchurch, New Zealand, some $3500 \mathrm{~km}$ away. None of the aircraft available in Antarctica had the capacity to take the injured from Molodezhnaya to McMurdo $(2900 \mathrm{~km})$. At the request of the Soviet Government the US Navy sent a Hercules with relief crews and medical teams from New Zealand to McMurdo to Molodezhnaya and return, $11500 \mathrm{~km}$ in 29 hours, with two refuelling stops in Antarctica. As there is a neurosurgical unit in Dunedin we received the unconscious man three days after the accident.

\section{Dunedin at work}

The patient was deeply unconscious with a right hemiplegia and in considerable respiratory distress. He also had fractured ribs and a mediastinal haematoma. A transfemoral arch aortogram excluded an intracranial haematoma and mediastinal vessel damage. He was nursed in the intensive care unit, and a tracheostomy with controlled ventilation was needed. Eventually

Department of Surgery, University of Otago Medical School, and Neurosurgical Unit, Dunedin Hospital, Dunedin, New Zealand R G ROBINSON, CHM, FRCS, professor of neurosurgery HELEN E WILLIAMS, RN, charge nurse his condition stabilised-a chronic vegetative state with a right hemiplegia. The tracheostomy could not be dispensed with owing to feeble coughing, and suction might be needed several times an hour. Feeding was by nasogastric tube, and there was an indwelling urethral catheter. His weight was $90 \mathrm{~kg}$ and height $1.78 \mathrm{~m}$. After six weeks there was little further improvement, and we were asked to plan his transfer to Moscow by commercial aircraft.

The plan was to fly by Air New Zealand (ANZ) from Dunedin via Auckland to Singapore and there pick up an Aeroflot connection to Moscow. Minimum requirements necessitated stopovers of at least 24 hours at Auckland and Singapore, with hospital special care facilities available. A stretcher and a generous supply of oxygen were to be available in all aircraft and he would be accompanied by a doctor and a nurse, who were to have hotel accommodation at stopovers. A day was set after which the patient would be ready to travel. We would accompany the patient to Singapore and offered to go the whole way to Moscow if desired by the Soviet Government.

Commercial airlines provide facilities for the transport of invalids but the care of the patient is the total responsibility of the accompanying team. All the nursing requirements during 10 hours in the special-care ward were noted, as this was the flight time between Auckland and Singapore. The major problem was respiratory care, and constantly available suction had to be provided not only in flight but for the ground transfers. We had seen a rechargeable battery-powered suction apparatus but it was not available to us. In the event this was just as well, as the use of battery-driven equipment contravenes many commercial aircraft regulations, although equipment can be connected up to the electrical systems of the aircraft. Instead we obtained a foot-operated Ambu sucker. This turned out to be ideal; it could be used everywhere without reference to other power sources, besides having excellent suction. An Ambu bag was obtained in case the patient had to be respirated. The necessary medical certificates were supplied to Air New Zealand. A team was selected, with reserves if needed; the members were known to be physically fit from recent performance and thought to be in possession of their wits. 
There was a fortnight of total silence from the Soviet Embassy, then on a Monday morning when one of us (RGR) was out of Dunedin on a consultation visit the Royal New Zealand Air Force telephoned to say that the journey would begin the coming Thursday and that the team was to take the patient to Moscow. Then the pressures were on-the activities of the Soviet Embassy, which was to arrange things in Singapore and onwards, its shipping agents (which handled details), ANZ, and the RNZAF - to say nothing of ourselves-had to be co-ordinated into one travel plan. Indeed, much of the plan for when we had left New Zealand had to be taken on trust. The generous assessment of equipment for 10 hours (converted to disposable items) was multiplied by three. We did not forget a ball of string, some adhesive tape, and a pocket knife. Everything was packed into two bright blue nylon duffle bags, one containing the essential life-support gear and the other the less important nursing stores. These bags were to accompany us everywhere. We were assured that the patient was not likely to need oxygen at the usual cabin pressures at $1500-1600 \mathrm{~m}$ altitude, but clearly it had to be available. The only drugs taken were diazepam for the patient, and aspirin and nitrazepam for the team.

As the patient was a well-covered man $(90 \mathrm{~kg})$ we did not need to worry about his energy needs so long as water and electrolyte requirements were met via the nasogastric tube. Two days before leaving the high-energy tube feed was stopped, and the nursing staff cleaned out the patient's bowels. This was to good effect as he had no faecal incontinence all the way to Moscow. The day before leaving all the gear was tried out, and each of us became familiar with all the equipment. A cuffed Portex tracheostomy tube was substituted for the metal one. The nasogastric tube and the urinary catheter were changed.

\section{On the way}

We slipped out of Dunedin Hospital in the middle of the Thursday afternoon in poor weather. On the way to the airport the patient became uncharacteristically distressed with increased tracheal secretions, and to settle him he was given $5 \mathrm{mg}$ intramuscular diazepam. This was to be the last medication. After a long wait we were loaded through the stern door of an RNZAF Andover. On the three-hour journey to Auckland the patient was largely cared for by the accompanying RNZAF matron. The cabin pressure did not go above $350 \mathrm{~m}$. By the time we arrived at Auckland in poor weather the patient's respiratory condition had deteriorated. We had underestimated the problem of humidification, and he would be better off without sedation. He was transferred to the neurosurgical unit at Auckland Hospital and soon improved. We did not sit down to a meal until 2200 .

The next day ANZ issued tickets and pre- and in-flight arrangements were discussed. There seemed to be many unknowns, so we visited the ANZ maintenance base at Mangere. There we became familiar with the loading plan and the set-up in the aircraft. Oxygen was from self-contained bottles and delivered at set rates of either 2 or $71 / \mathrm{min}$. Next we discussed humidification with the respiratory department at Auckland Hospital. We had with us an upright Hudson's humidifier that could not be used for a recumbent patient without an extension tube. This was acquired and also a supply of sodium bicarbonate solution to drip through the tracheostomy tube if needed.

\section{Auckland-Singapore}

We collected the patient at 0800 on the Saturday and at the airport underwent the most rigorous security check of the trip. At the airports HEW looked after the patient and RGR dealt with the airlines and the ground crews. The loading into the DC-10 was through the first-class galley, which is not serviced until such loading has been completed. In the aircraft ANZ's stretcher, which has a tiltable head, sat on a plinth over the right-hand seats of the forward tourist compartment. There were side curtains, but it was uncomfortably hot if they were kept fully closed the whole time. The only problem was to fix the humidifier in an upright position, and eventually it was taped to the ledge of the window blind and then run on 21 oxygen $/ \mathrm{min}$. No further problems of humidification were encountered in the air. The value of the oxygen was to run the humidifier only. By the time of take-off at 1130 a routine was established that was to be followed for the rest of the way. Regular hourly observations of pulse, respirations, and temperature were recorded and fluid balance charts kept. The patient was turned two hourly-a struggle in a DC-10 with a heavy patient as one cannot get on the outer side for leverage. Initially he was given $100 \mathrm{ml}$ water hourly but as urinary output was low this was increased to $200 \mathrm{ml}$ hourly, a rate that was continued to Moscow. Frequent tracheal suction was needed, and we had with us 100 disposable intratracheal catheters. We alternated duties completely, and the off-duty person had no calls at all. We co-ordinated at turning time. To our gratification it proved no more difficult to care for him in the air than it had been in the ward. The flight was longer than scheduled as the Australian air controllers were out on strike and the flight was diverted away from Australian air space through Port Moresby and Papua New Guinea.

We arrived at Singapore at 1830 local time, and before landing we had no clear idea about facilities there. The ground crew was unfamiliar with stretcher unloading but we remembered the drill from Auckland. Representatives from the Soviet Embassy at Singapore met us, and we went by ambulance to Mount Alvernia Hospital, where we handed the patient over to its excellent intensive care unit. Then to our hotel-it was to be 2100 before a shower and a meal.

\section{Limbo}

The next day had been planned as a rest day for the benefit of the patient, but it was only too apparent that for this Sunday our need was even greater as we had been on the go for six days. Some New Zealanders kindly took us on the harbour and we relaxed and swam in the warm sun.

The flight was to leave at 2300 on the Monday for Moscow by Aeroflot. There were delays with the incoming flight, and we did not know until around 2300 that departure would be the next morning. A frustrating day, but at least the patient was well cared for in hospital. At 0800 on the Tuesday a car from the Soviet Embassy collected us to go to the hospital. The trip was only just made before the car's clutch (Japanese) finally gave out. After collecting the patient in the ambulance we separated from the Soviet party. At the airport there was confusion as we had our own tickets but not that of the patient. No way could the computer be made to read out the flight confirmation, although the traffic officers knew all about it. After a trying wait in the heat the Soviet group arrived and the computer was put at ease. At 1000 we were loaded into an Aeroflot IL-62, an aircraft like a VC-10. All the left-hand seats of the forward tourist compartment had been removed and replaced by a low divan, $1 \times 2 \mathrm{~m}$. The Aeroflot ground staff improvised an adaptor from their portable oxygen bottles to the humidifier tubing; the valves of these bottles worked the reverse way to the ANZ ones. The humidifier was strung to one of the roof ventilators (figure). We had no difficulty in establishing routine care on exactly the same lines as previously. Certainly it was easier to turn the patient, as one could get on each side and the divan was low. To our surprise nothing happened and no other passengers arrived. Fortunately the aircraft was connected to an air conditioner but it was still rather warm. We could get little out of the cabin crew, who became evasive-as is commonplace in these circumstancesand the flight crew stayed up front. Eventually the Singapore security guards told us that there was a mechanical defect and communications with Moscow had been lost owing to bad 


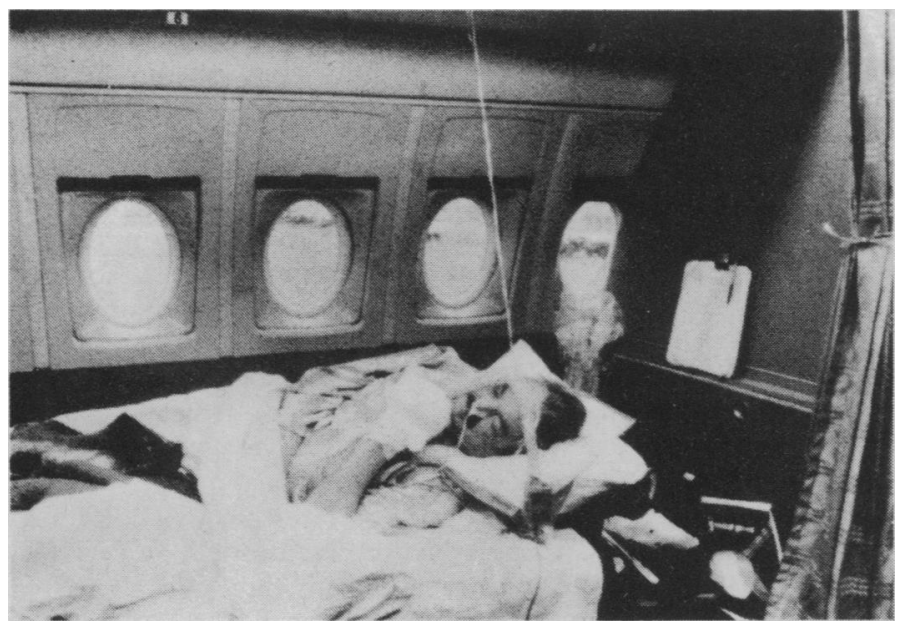

Patient in a Soviet IL-62 on a low divan with tubing to Hudson's humidifier strung from a roof ventilator.

weather. Nothing could happen without authorisation from Moscow. At 1300 lunch with wine was served. Suddenly at 1400 the flight crew bustled out into a car, and the flight was cancelled. So we were unloaded, and we had a long wait in the airport lounge while an ambulance came out from Singapore and took us back to the same hospital, where the staff put on a brave face at having the patient back with only 10 minutes' notice. By this time we had discovered that a spare part was being flown out from the Soviet Union and that perhaps we would get away the next evening.

\section{Through the night}

The next morning, Wednesday, Aeroflot confirmed a departure time of 1830 that evening. This time there were no hitches, and we were loaded into the same aircraft with the same crew at 1715 . We had the whole section of the aircraft to ourselves except for a packing case containing the defective engine fire extinguisher. Care of the patient continued as before. The lavatory in our section had no water, but the full first-class section did not seem to mind our taking full urine bags to that lavatory for emptying. Once into the night the routine varied a little-if the person off duty was still asleep at changeover time this was allowed to continue until he or she woke spontaneously. Each did get one reasonable spell of sleep in the 18 hours. The night was interminable and hot. The cabin heating either worked full on or not at all. The first staging point was Delhi, which we reached at 0030 local time for a two-hour refuelling stop. The crew were changed, the passengers all went off, and we stayed on board with the patient.

We reached Tashkent, the last staging point, in the very early morning. There immigration formalities took two hours, and we were the only ones to remain on board except for the many security guards. As our status was known all the paper work was done without us. Outside it was $10^{\circ} \mathrm{C}$, all the aircraft doors were open, and there was no heating, so now we became rather cool.

We landed at Moscow's Sheremtyevo International Airport at 0715 in the most dubious conditions imaginable through a snow storm. The outside temperature was $-3^{\circ} \mathrm{C}$. Before landing the patient had been washed, shaved, and changed for the last time, and he looked as well as he had done when he left Dunedin six days before. There is no unloading by bays and we all had to cross the tarmac to reach the terminal building. A reception party from the Ministry of Civil Aviation met us with an interpreter, doctors, and a stretcher party. We handed over the patient and the bags containing the gear with a feeling of relief.

At the Botkin Hospital we saw the admitting medical officers.
There was a trying dialogue as they spoke no English and although our interpreter had excellent English he knew no medicine. We had brought full notes, but we were stretched to the utmost to explain in very basic English the history of the patient. It was not easy to say why we did not have serial EEGs and why we had not tried hyperbaric oxygen. They were singularly unimpressed with our computed tomogram, which showed large holes in the patient's brain. Nevertheless, he seemed in good hands and he was in Moscow at last.

A week later we made a special trip to see him before leaving for home. He was well cared for but manifestly would never improve from his chronic vegetative state. This was now accepted by his physicians and sadly conveyed to the patient's wife with our participation. He was to die on 5 July 1979.

\section{Debriefing}

With adequate organisation very seriously ill patients can travel almost any distance by commercial aircraft. Although space is readily provided, the patient's escorts are expected to manage him and deal with any expected complications, and must be equipped to do so. For long distances realistic support must be provided. After all, the patient and the team may be at $12000 \mathrm{~m}$ for 10 hours - there is no way of getting hold of anything that has been missed, and there are narrow limits to improvisation. The sole demands on the patient's behalf that we made on the cabin crews were for hot and cold water and for rubbish bags for the disposable items. Despite the high technology of the modern jet aircraft the management of the patient must be reduced to its simplest level-preferably to be carried out with man as the sole additional power source. While oxygen will be available and equipment can be connected up to the electrical system of the aircraft, for such a complex trip as ours everything had to be at its most basic and on a fail-safe basis. Any accompanying party should realise that the day will be long and that refuelling stops give no relief. A 10-hour direct flight may have another four hours' or more added care of the patient just to get in and out of the international airports at either end, let alone any transfer time from hospital to airport. This must be allowed for in the calculation of supporting needs. Fortunately our initial assessment had been very generous, and despite delays there was a surplus. The errors made about humidification and sedation could luckily be rectified at the first stopover. To all this the effects of jet lag have to be added. If there is an airline interchange overnight accommodation in hospital should be arranged for the patienteven if he does not need a rest the team may, and they should be reasonably housed. From our experience of sending other severely ill patients overseas from New Zealand, no accompanying party should be less than two, and relatives are not an adequate substitute. Even if the second person has not much to do he provides suitable back-up. If there are administrative hassles at airports or delays then one can deal with these and the other concentrate on the patient. We were fortunate as we could rely on Soviet diplomatic staff when things went wrong but it could be otherwise. Perhaps we take a gloomy view of air travel, but when the care of a patient is at stake all contingencies must be catered for.

It would be pleasant to record that our separate journeys back from Moscow were incident free, but this was not so. One of us came back through London and Hong Kong, and no flight left anywhere near on time. There were major aircraft breakdowns at Bangkok and Hong Kong, and a gross error with tickets. The other came back through Australia, only to be held up by a strike of New Zealand engineers. All frustrating for an ordinary passenger but of great concern to anyone with a sick patient.

An ox would be a suitable mascot for those undertaking the type of journey we have described. Quite apart from the physical toil, they need endless patience and persistence without loss of temper and an ability to function at a primitive level. 